\title{
Surface Integrity Analysis and Simultaneous Optimization Using Taguchi Grey Relational Analysis
}

\author{
Prathipati Raju ${ }^{*}$, Ch. Ratnam ${ }^{2}$ and Dora Siva Prasad ${ }^{3}$ \\ ${ }^{1,3}$ Department of Mechanical Engineering, GIT, GITAM deemed to be University, \\ Visakhapatnam, India \\ ${ }^{2}$ Professor and HOD, Department of Mechanical Engineering, Andhra University, \\ Visakhapatnam, India \\ 1prathipatiraju25@gmail.com, ${ }^{2}$ chratnam@gmail.com, \\ ${ }^{3}$ dorasivaprasad@gmail.com
}

\begin{abstract}
Wire electric discharge machining (WEDM) is one of the most extensively used non conventional material removal process as it provides an effective solution for machining of hard materials with complex shapes. The selection of optimum combination of process parameters is a difficult task in WEDM as it is affected by large number of input parameters. From the literature, Pulse on time, peak current, servo voltage and wire tension are found to be the most influencing parameters and hence these parameters are considered in the present work. In any machining process, the surface roughness is a key factor that influences the properties of the materials such as wear resistance, corrosion resistance, fatigue life and so on. Cutting speed plays an effect on the economics of production. This paper presents an investigation on 316 L SS machined by WEDM to the study the effect of surface roughness and cutting speed. Experimentation were conducted by using full factorial design of experiment under different conditions of input parameters by using brass wire and demineralised water as dielectric fluid. Using Analysis of variance, the significance of the parameters is found and their optimal combination of parameters for surface roughness and cutting speed is obtained. In order to optimize surface roughness and cutting speed simultaneously, Taguchi based grey relational analysis is used to determine the optimal setting of process parameters for multiple machining characteristics. Surface integrity studies are also carried out on the machined surface. Scanning electron microscope is used to study the surface morphology of WEDMed surface.
\end{abstract}

Keywords: WEDM, ANOVA, surface roughness, cutting speed, grey relational analysis, surface integrity

\section{Introduction}

Machining with accuracy and precision is very important in tool and die industries. Machining hard materials with traditional machining methods result in very high cutting forces and very poor surface finish. The materials that are difficult to machine by traditional machining methods such as turning, milling and drilling can be machined by nontraditional machining process such as ultra sonic machining, electro chemical machining and electric discharge machining [1]. Ultra sonic machining may give better results when compared to traditional machining methods, but precise and complex shapes are very much difficult to generate.

Wire electrical discharge machining is a form of electric discharge machining and plays a very important role in the current precision manufacturing environment as

Received (December 21, 2017), Review Result (March 1, 2018), Accepted (March 6, 2018) 
these are used to cut conductive materials of any hardness [2]. WEDM is widely used because it can be fully automated and flexible in making complex geometrical shapes in one setup. This process capability is particularly important for aero-engine manufacture. The mechanism involved in the material removal process of WEDM is due to melting and vaporization caused by the electric spark discharge generated by a pulsating direct current power supply between the electrodes. In WEDM, the moving wire is a negative electrode whereas the work piece is a positive electrode. The sparks will generate between two closely spaced electrodes under the influence of dielectric fluid [3]. These sparks generate craters, micro cracks and recast layer on the machined surface [4]. Since WEDM is a thermal dominant process, the very high temperature generated by sparks has significant impact on surface integrity including surface topography, micro structural change, residual stress, micro hardness, and element distributions. The heat affected zone with a white layer is often associated with high tensile residual stress, micro cracks, porosity, grain growth, and alloying from the tool electrode or dielectric fluid [5]. WEDM setting parameters and work piece material and the wire electrode influence the nature of the surface produced to a varying degree [6]. Even when different materials are machined under the same machining conditions yield different machining characteristics [7]. Selection of optimum machining parameter combinations for obtaining higher cutting efficiency and dimensional accuracy is a challenging task in WEDM because of the presence of large number of process variables and complicated stochastic process mechanism [8]. There is lot of research work carried out on parametric study and development of empirical models on WEDM process and also development of mathematical models through design of experiments to model cutting speed and surface finish. The Taguchi method has been widely used in several industrial fields and research work for this study. Combination of the Taguchi method and Genetic Algorithm to optimize material removal rate, surface finish, and kerf in WEDM is employed [9]. Using Taguchi's parameter design, significant machining parameters affecting the performance measures were identified. The relationship between control factors and responses like MRR, surface finish, and kerf were established. The Taguchi method is used to determine optimal parameter settings in WEDM [10]. Taguchi method was designed to optimize only a single performance characteristic. The Grey relational analysis has been proved to effectively resolve the complicated inter-relationships among multiple performance characteristics of the EDM process. Optimization of the turning operation with multiple performance characteristics using Taguchi method and grey relational analysis for SKD 11 tool steel is investigated [11]. Simultaneous optimization is performed by obtaining grey relational grade using grey relational analysis during electrochemical polishing of the stainless steel [12]. Optimal machining parameters were determined by the grey relational grade as the performance index. It was observed that the performance characteristics of surface roughness and passivation strength are improved. The most significant response variables in WEDM are cutting speed (Cs) and surface roughness (Ra) of workpiece. $\mathrm{Ra}$ is a machining characteristic that plays a crucial role in determining the quality of engineering components. A good quality surfaces improve fatigue strength, corrosion and wear resistance of the work piece. It is well known fact that a high $\mathrm{Cs}$ and very good $\mathrm{Ra}$ can never be achieved simultaneously in WEDM process.

This paper presents the effect of WEDM machining parameters namely pulse on time $\left(\mathrm{T}_{\mathrm{ON}}\right)$, peak current(IP), servo voltage(SV) and wire tension(WT) on the most important machining criteria, $\mathrm{Ra}$ and $\mathrm{Cs}$ by taking two levels of each parameter. For optimal combination of process parameters, Taguchi method is used to improve processes with single performance characteristics. However, traditional Taguchi 
method cannot solve multi objective optimization problem. To overcome this, the Taguchi method coupled with grey relational analysis is employed. Regression equation is also developed from Minitab software for individual machining characteristics. Simultaneous optimization is performed for obtaining best $\mathrm{Ra}$ and Cs. Microstructural analysis is carried out to study the effect of machining parameters on the machined surface.

\section{Experimental Design}

The material used in this study is $316 \mathrm{~L} \mathrm{SS}$, which is mostly used as die material owing to its properties. The chemical composition of $316 \mathrm{~L} \mathrm{SS}$ is given in Table 1. All the specimens were machined on Japax LDM 50 Wire EDM machine. Taguchi $\mathrm{L}_{16}$ orthogonal array with four parameters and two levels are considered for experimentation and $\mathrm{Ra}$ and $\mathrm{Cs}$ are the response parameters. The process parameters and their levels are presented in Table 2.

Table 1. Chemical Composition of 316 L SS

\begin{tabular}{|c|c|c|c|c|c|c|c|c|}
\hline $\mathrm{C}$ & $\mathrm{Cr}$ & $\mathrm{Si}$ & $\mathrm{S}$ & $\mathrm{Mo}$ & $\mathrm{Mn}$ & $\mathrm{Ni}$ & $\mathrm{P}$ & $\mathrm{Fe}$ \\
\hline 0.017 & 17.6 & 0.56 & 0.001 & 2.16 & 1.21 & 11.1 & 0.025 & $\mathrm{Bal}$ \\
\hline
\end{tabular}

Table 2. Machining Parameters and their Levels

\begin{tabular}{|c|c|c|c|c|c|}
\hline S.No & Parameters & Symbol & Level 1 & Level 2 & Units \\
\hline 1 & Pulse On time & T ON & 15 & 25 & $\mu$ Sec \\
\hline 2 & Peak current & IP & 9 & 12 & Ampere \\
\hline 3 & Servo voltage & SV & 5 & 15 & Volts \\
\hline 4 & Wire tension & WT & 5 & 12 & Kg-f \\
\hline
\end{tabular}

Specimens of size $13 \times 12 \times 6 \mathrm{~mm}^{3}$ were machined by varying the cutting parameters. Brass wire is used as wire electrode with demineralised water as dielectric fluid. A total of 16 experiments were conducted as per L16 orthogonal array [13]. Ra was obtained by measuring the mean absolute deviation using a stylus-type profilometer, Mitutoyo SJ-310. Roughness measurements, in the transverse direction, on the work pieces have been repeated three times and their average have been recorded with a cut off length of $0.8 \mathrm{~mm}$. The Cs during machining was displayed digitally on the screen of WEDM machine and the values are taken in $\mathrm{mm} / \mathrm{min}$ for all the specimens and are tabulated. The values of the data acquired for $\mathrm{Ra}$ and $\mathrm{Cs}$ respectively along with their $\mathrm{S} / \mathrm{N}$ ratios for the L16 orthogonal array parameter combination are presented in Table 3. Optimization of individual machining characteristics is performed for $\mathrm{Ra}$ and $\mathrm{Cs}$ using Taguchi design. The effect of input parameters on Ra and Cs in WEDM process of 316L SS has been analyzed individually. Also simultaneous optimization of response parameters for $\mathrm{Ra}$ and $\mathrm{Cs}$ is carried out using Taguchi grey relational analysis to find the optimal combination of input parameters for machining. SEM images are obtained for the machined specimens and the nature of surface is analyzed. 
Table 3. Acquired Data as per L16 Orthogonal Array

\begin{tabular}{|c|c|c|c|c|c|c|}
\hline $\mathrm{SNo}$ & $\mathrm{T}_{\mathrm{ON}}$ & $\mathrm{IP}$ & $\mathrm{SV}$ & $\mathrm{WT}$ & $\mathrm{Ra}$ & $\mathrm{Cs}$ \\
\hline 1 & 15 & 9 & 5 & 5 & 2.69 & 1.41 \\
\hline 2 & 15 & 9 & 5 & 12 & 1.535 & 0.97 \\
\hline 3 & 15 & 9 & 15 & 5 & 2.1 & 0.84 \\
\hline 4 & 15 & 9 & 15 & 12 & 2.22 & 1.23 \\
\hline 5 & 15 & 12 & 5 & 5 & 2.605 & 1.38 \\
\hline 6 & 15 & 12 & 5 & 12 & 2.125 & 1.36 \\
\hline 7 & 15 & 12 & 15 & 5 & 2.35 & 1.29 \\
\hline 8 & 15 & 12 & 15 & 12 & 2.16 & 1.08 \\
\hline 9 & 25 & 9 & 5 & 5 & 3.005 & 1.93 \\
\hline 10 & 25 & 9 & 5 & 12 & 2.965 & 1.52 \\
\hline 11 & 25 & 9 & 15 & 5 & 2.85 & 1.78 \\
\hline 12 & 25 & 9 & 15 & 12 & 3.03 & 1.64 \\
\hline 13 & 25 & 12 & 5 & 5 & 3.425 & 2.2 \\
\hline 14 & 25 & 12 & 5 & 12 & 3.435 & 2.18 \\
\hline 15 & 25 & 12 & 15 & 5 & 3.3 & 2.04 \\
\hline 16 & 25 & 12 & 15 & 12 & 3.32 & 2.32 \\
\hline
\end{tabular}

\section{Results and Discussions}

Optimization of machining characteristics is performed individually using Taguchi method and simultaneous optimization was done using Taguchi grey relational analysis. Surface of the machined specimens are analyzed by obtaining their SEM images.

\subsection{Optimization of Individual Machining Characteristics}

Optimization of individual machining characteristics is done for both Ra and Cs. Signal to noise ratio $(\mathrm{S} / \mathrm{N})$ was done to the desirable value of output characteristics. The optimal combination of the input parameter is obtained by identifying the largest values of $\mathrm{S} / \mathrm{N}$ ratios. Analysis of variance for both $\mathrm{Ra}$ and $\mathrm{Cs}$ is calculated individually and the most significant input parameters are identified. Optimal values for Ra and Cs are predicted. Regression equation for input and output characteristics are calculated by using Minitab16 software. The values of response obtained from the optimal combination are compared with the predicted values.

\subsubsection{S/N Ratios for Individual Machining Characteristics}

$\mathrm{S} / \mathrm{N}$ ratios for $\mathrm{Ra}$ and $\mathrm{Cs}$ are calculated by using equation 1 and 2 respectively. 


$$
\begin{aligned}
& S / N=-10 \log \frac{1}{n} \sum_{i=1}^{n} y^{2} \\
& S / N=-10 \log \frac{1}{n} \sum_{i=1}^{n} 1 / y^{2}
\end{aligned}
$$

The response of means and $\mathrm{S} / \mathrm{N}$ ratios for $\mathrm{Ra}$ and $\mathrm{Cs}$ are presented in Table 4 and Table 5 respectively.

\begin{tabular}{|c|c|c|c|c|c|c|c|c|c|}
\hline \multicolumn{5}{|c|}{ Mean Ra } & \multicolumn{5}{|c|}{ Mean Cs } \\
\hline $\begin{array}{c}\text { Level/Process } \\
\text { parameters }\end{array}$ & $\mathrm{T}_{\mathrm{ON}}$ & IP & SV & WT & $\begin{array}{c}\text { Level/Process } \\
\text { Parameters }\end{array}$ & $\mathrm{T}_{\mathrm{ON}}$ & IP & SV & WT \\
\hline 1 & 2.223 & 2.549 & 2.723 & 2.791 & 1 & 1.195 & 1.415 & 1.619 & 1.609 \\
\hline 2 & 3.166 & 2.84 & 2.666 & 2.599 & 2 & 1.951 & 1.731 & 1.527 & 1.538 \\
\hline
\end{tabular}

Table 4. Response Table of Means for Ra and Cs

\begin{tabular}{|c|c|c|c|c|c|c|c|c|c|}
\hline \multicolumn{5}{|c|}{ S/N Ratio for Ra } & \multicolumn{5}{|c|}{ S/N Ratio for Cs } \\
\hline $\begin{array}{l}\text { Level/Process } \\
\text { parameters }\end{array}$ & $\mathrm{T}_{\mathrm{ON}}$ & IP & SV & WT & $\begin{array}{l}\text { Level/Process } \\
\text { Parameters }\end{array}$ & $\mathrm{T}_{\mathrm{ON}}$ & IP & SV & WT \\
\hline 1 & -6.833 & -7.926 & -8.449 & -8.812 & 1 & 1.419 & 2.707 & 3.894 & 3.78 \\
\hline 2 & -9.991 & -8.897 & -8.375 & -8.012 & 7 & 5.722 & 4.434 & 3.246 & 3.361 \\
\hline
\end{tabular}

Table 5. Response Table of Signal to Noise Ratios for Ra and Cs

\subsubsection{Effect of Process Parameters for Individual Machining Characteristics}

Figure 1 and 2 shows the plots of $\mathrm{S} / \mathrm{N}$ ratios for Ra and Cs respectively. Optimal parameters for best $\mathrm{Ra}$ is obtained when machined at $\mathrm{T}_{\mathrm{ON}}=15 \mu \mathrm{s}, \mathrm{IP}=9 \mathrm{~A}, \mathrm{SV}=15 \mathrm{~V}$ and $\mathrm{WT}=12 \mathrm{Kg}-\mathrm{f}$, whereas best $\mathrm{Cs}$ is achieved at $\mathrm{T}_{\mathrm{ON}}=25 \mu \mathrm{s}, \mathrm{IP}=12 \mathrm{~A}, \mathrm{SV}=5 \mathrm{~V}$ and $\mathrm{WT}=5 \mathrm{Kg}$ f.

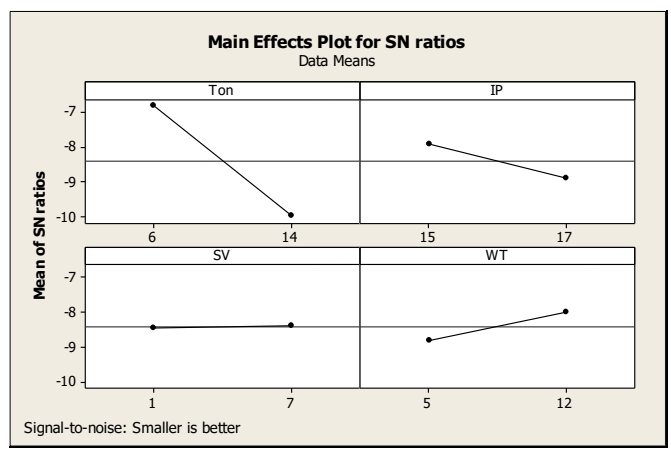

Figure 1. Plot of S/N Ratio for Ra

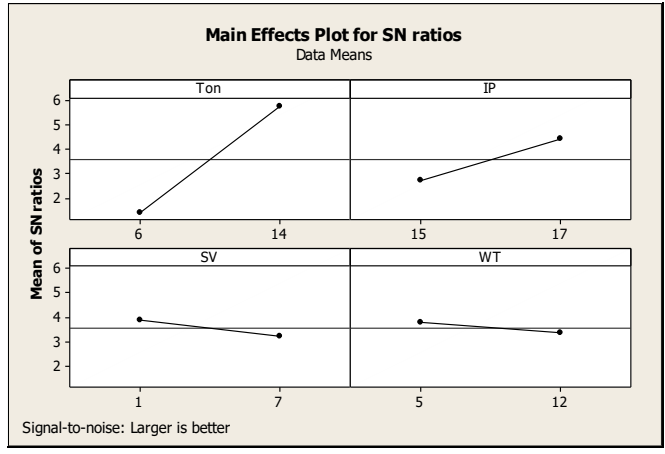

Figure 2. Plot of S/N Ratio for Cs

\subsubsection{Analysis of Variance (ANOVA) for Individual Machining Characteristics}

ANOVA is performed to study the effect of parameters on the machining. From the results of ANOVA presented in Tables 6 and 7, $\mathrm{P}$ value for the parameters $\mathrm{T}_{\mathrm{ON}}$ and IP is less than 0.05 and hence it can be concluded that these are the most significant parameters that effects Ra and Cs. 
Table 6. ANOVA Table for Ra

\begin{tabular}{|c|c|r|r|r|r|}
\hline Source & DF & Seq SS & Adj MS & \multicolumn{1}{c|}{ F } & \multicolumn{1}{c|}{ P } \\
\hline TON & 1 & 3.55794 & 3.55794 & 52.188 & 0.000017 \\
\hline IP & 1 & 0.33785 & 0.33785 & 4.9556 & 0.04785 \\
\hline SV & 1 & 0.01294 & 0.01294 & 0.1898 & 0.671516 \\
\hline WT & 1 & 0.14726 & 0.14726 & 2.1601 & 0.169651 \\
\hline Error & 11 & 0.74993 & 0.06818 & & \\
\hline Total & 15 & 4.80592 & & & \\
\hline
\end{tabular}

Table 7. ANOVA Table for Cs

\begin{tabular}{|c|c|r|r|r|r|}
\hline Source & DF & \multicolumn{1}{|c|}{ Seq SS } & \multicolumn{1}{c|}{ Adj MS } & \multicolumn{1}{c|}{ F } & P \\
\hline TON & 1 & 2.28766 & 2.28766 & 59.2352 & 0.000009 \\
\hline IP & 1 & 0.40006 & 0.40006 & 10.3588 & 0.008181 \\
\hline SV & 1 & 0.03331 & 0.03331 & 0.8624 & 0.372994 \\
\hline WT & 1 & 0.02031 & 0.02031 & 0.5258 & 0.483519 \\
\hline Error & 11 & 0.42482 & 0.03862 & & \\
\hline Total & 15 & 3.16614 & & & \\
\hline
\end{tabular}

\subsubsection{Predicted Optimal Values of Individual Machining Characteristics}

The predicted optimal values of $\mathrm{Ra}$ and $\mathrm{Cs}$ are calculated by using equation 3

$$
\eta_{\text {opt }}=\eta_{m}+\sum_{i=1}^{n}\left(\eta_{i}-\eta_{m}\right)
$$

where, $\eta_{\text {opt }}$ is optimal value of machining characteristics, $\eta_{m}$ is total mean of machining characteristics, $\eta_{i}$ is mean values at the optimum level and $\mathrm{n}$ is the number of process parameters. The predicted optimal combination values for $\mathrm{Ra}$ and $\mathrm{Cs}$ are obtained as $1.953 \mu \mathrm{m}$ and $2.19 \mathrm{~mm} / \mathrm{min}$ respectively.

\subsubsection{Mathematical Model to Relate the Parameters with Responses}

Multiple linear regression models are an adequate representation of a more complicated structure, within certain ranges of the independent variables and their generalized model gives the relationship between response and independent variables $[14,15]$. The equations 4 and 5 show linear regression equations obtained with Minitab16 software for Ra and Cs respectively.

$$
\begin{aligned}
& \mathrm{Ra}=0.0811161+0.0943125 \mathrm{Ton}+0.096875 \mathrm{IP}-0.0056875 \mathrm{SV}-0.0274107 \mathrm{WT} \\
& \mathrm{Cs}=-0.368482+0.075625 \mathrm{Ton}+0.105417 \mathrm{IP}-0.009125 \mathrm{SV}-0.0101786 \mathrm{WT}
\end{aligned}
$$

The predicted and experimental values of $R_{a}$ and $C_{s}$ at optimal combination are presented in Table 8 . It could be observed that, the predicted values are very close to the experimental values and also with regression equation values, which give the optimal combination of parameters to achieve best results for the Ra and Cs individually.

\subsection{Multi Response Optimization using Grey Relational Analysis}

Grey theory provides an efficient solution to the uncertainty, multi input and discrete data problem. The relationship between machining parameters and machining performance can be found out by using grey relational analysis coupled with Taguchi [1620]. Grey relational analysis is performed in a step wise manner and are calculated as follows. 


\section{Step 1: Normalization of experimental result}

Data preprocessing is a process of transforming the original sequence to a comparable sequence and for this purpose the experimental results are normalized in the range between 0 and 1 . For Ra, normalization is done by using equation 6 and where as for Cs, normalization is done by using the equation 7 .

$$
\begin{aligned}
x_{i}^{*}(k) & =\frac{\max x_{i}^{0}(k)-x_{i}^{0}(k)}{\max x_{i}^{0}(k)-\min x_{i}^{0}(k)} \\
x_{i}^{*}(k) & =\frac{x_{i}^{0}(k)-\min x_{i}^{0}(k)}{\max x_{i}^{0}(k)-\min x_{i}^{0}(k)}
\end{aligned}
$$

Where, $x_{i}^{*}(k)$ is the sequence after the data processing, $x_{i}^{0}(k)$ is the original sequence, $i=1,2 \ldots \mathrm{m}$ and $k=1,2 \ldots \mathrm{n}$ with $\mathrm{m}=16$ and $\mathrm{n}=2 . x^{0}$ is the desired target value

\section{Step 2: Deviation Sequence}

The deviation sequence ${ }^{\Delta} O_{i}(k)$ is the absolute difference between reference sequence and comparable sequence, calculated by using the equation 8 .

$$
\Delta O_{i}(k)=\left|x_{i}^{o}(k)-x_{i}^{*}(k)\right|
$$

\section{Step 3: Grey Relational Coefficient}

Grey relational coefficient (GRC) establishes the relationship between the ideal and actual normalized values and is expressed by using equation 9 .

$$
\xi_{i}(k)=\frac{\Delta \min +\varsigma \max }{\Delta \boldsymbol{O}_{i}(k)+\varsigma \max }
$$

Where $\xi_{i}(k)$ is the grey relational co-efficient, $\varsigma_{\text {is }}$ the distinguishing coefficient lying between 0 and $1 . \varsigma$ is taken as $0.5 . \Delta \min$ is the smallest value of ${ }^{\Delta} \boldsymbol{O}_{i}(k)$ and $\Delta \max _{\text {is the largest value of }} \Delta_{\boldsymbol{O}_{i}}(k)$. Since GRC is concerned with individual response parameter, for evaluation of multi response parameters, Grey Relation Grade (GRG), $\gamma$, is to be calculated.

\section{Step 4: Grey Relational Grade}

GRG indicates the degree of influence exerted on the reference sequence by the comparable sequence and basing upon the influence of quality characteristics on overall process performance, the weights are assigned to individual GRGs and the resultant GRG is coined as weighted grey relational grade as shown in equation 10.

$$
\gamma_{i}=\frac{1}{m} \sum_{k=1}^{m} w_{i} \xi_{i}(k)
$$

where $\mathrm{m}$ is the number of process output responses and $w_{1}$ and $w_{2}$ are the weights associated with individual characteristics. A total of three cases are considered.

Case: 1 For balanced $\mathrm{Ra}$ and $\mathrm{Cs}$, equal weights are assigned to both $\mathrm{Ra}$ and $\mathrm{Cs}, \mathrm{R}_{\mathrm{a}}$ is assigned a weight of $\left(\mathrm{w}_{1}\right)=0.5$ and $\mathrm{C}_{\mathrm{s}}$ with $\left(\mathrm{w}_{2}\right)=0.5$. 
Case: 2 For better surface roughness, $R_{a}$ is assigned a weight of $\left(w_{1}\right)=0.7$ and $C_{s}$ with $\left(\mathrm{w}_{2}\right)=0.3$.

Case: 3 For better cutting speed, $\mathrm{R}_{\mathrm{a}}$ is assigned a weight of $\left(\mathrm{w}_{1}\right)=0.3$ and $\mathrm{C}_{\mathrm{s}}$ with $\left(\mathrm{w}_{2}\right)=$ 0.7 .

The calculations of the entire grey relational analysis are presented in Table 9.

\section{Step 5: Optimal Combination of Process Parameters}

Largest value of GRG provides best multiple performance characteristics. From the Table 9 it is clear that for balanced $\mathrm{Ra}$ and $\mathrm{Cs}$ as well as for better surface roughness experiment 2 has largest value of GRG providing best multiple performance characteristics combination at $\mathrm{T}_{\mathrm{ON}}=15 \mu \mathrm{s}, \mathrm{IP}=9 \mathrm{~A}, \mathrm{SV}=5 \mathrm{~V}$ and $\mathrm{WT}=12 \mathrm{Kg}-\mathrm{f}$. But for better cutting speed experiment 16 has largest value of GRG providing best multiple performance characteristics combination at $\mathrm{T}_{\mathrm{ON}}=25 \mu \mathrm{s}, \mathrm{IP}=12 \mathrm{~A}, \mathrm{SV}=15 \mathrm{~V}$ and $\mathrm{WT}=$ $12 \mathrm{Kg}-\mathrm{f}$.

The results of best combination for individual characteristic optimization and simultaneous optimization of multiple characteristics are presented in Table 10.

Table 8. Results of Individual Machining Characteristic Optimization

\begin{tabular}{|l|l|l|l|l|}
\hline $\begin{array}{l}\text { Machining } \\
\text { characteristics }\end{array}$ & $\begin{array}{l}\text { Optimal parameter } \\
\text { combination }\end{array}$ & $\begin{array}{l}\text { Predicted } \\
\text { optimal value }\end{array}$ & $\begin{array}{l}\text { From regression } \\
\text { equation }\end{array}$ & Experimental value \\
\hline Ra & $\begin{array}{l}\text { TON=15 } \mu \mathrm{s}, \mathrm{IP}=9 \mathrm{~A}, \\
\text { SV=15Vand WT=12Kg-f }\end{array}$ & $1.953 \mu \mathrm{m}$ & $1.95 \mu \mathrm{m}$ & $2.22 \mu \mathrm{m}$ \\
\hline $\mathrm{Cs}$ & $\begin{array}{l}\text { TON }=25 \mu \mathrm{s}, \quad \mathrm{IP}=12 \mathrm{~A}, \\
\mathrm{SV}=5 \mathrm{~V} \text { and WT=5Kg-f }\end{array}$ & $2.19 \mathrm{~mm} / \mathrm{min}$ & $2.28 \mathrm{~mm} / \mathrm{min}$ & $2.2 \mathrm{~mm} / \mathrm{min}$ \\
\hline
\end{tabular}

Table 9. Calculations of Grey Relational Analysis

\begin{tabular}{|c|l|l|l|r|r|r|r|r|r|}
\hline SNo & $\begin{array}{l}\text { Normali } \\
\text { zation } \\
\text { of }\end{array}$ & $\begin{array}{l}\text { Normaliz } \\
\text { ation of } \\
\text { Cs }\end{array}$ & $\begin{array}{l}\text { Deviation } \\
\text { Sequence } \\
\text { for Ra }\end{array}$ & $\begin{array}{l}\text { Deviation } \\
\text { Sequence } \\
\text { for Cs }\end{array}$ & $\begin{array}{l}\text { GRC for } \\
\text { Ra }\end{array}$ & $\begin{array}{l}\text { GRC } \\
\text { for Ct }\end{array}$ & $\begin{array}{l}\text { GRG } \\
\text { With } \\
\text { W1= }\end{array}$ & $\begin{array}{l}\text { W1=0.7, } \\
\text { W2=0.3 }\end{array}$ & $\begin{array}{l}\text { W1-0.3, } \\
\text { W2=0.7 }\end{array}$ \\
\hline 1 & 0.3921 & 0.3851 & 0.6079 & 0.6149 & 0.4513 & 0.4485 & 0.4499 & 0.2252 & 0.22466 \\
\hline 2 & 1.0000 & 0.0878 & 0.0000 & 0.9122 & 1.0000 & 0.3541 & $\mathbf{0 . 6 7 7 0}$ & $\mathbf{0 . 4 0 3 1}$ & 0.27392 \\
\hline 3 & 0.7026 & 0.0000 & 0.2974 & 1.0000 & 0.6271 & 0.3333 & 0.4802 & 0.2695 & 0.21072 \\
\hline 4 & 0.6395 & 0.2635 & 0.3605 & 0.7365 & 0.5810 & 0.4044 & 0.4927 & 0.2640 & 0.22868 \\
\hline 5 & 0.4368 & 0.3649 & 0.5632 & 0.6351 & 0.4703 & 0.4405 & 0.4554 & 0.2307 & 0.22471 \\
\hline 6 & 0.6895 & 0.3514 & 0.3105 & 0.6486 & 0.6169 & 0.4353 & 0.5261 & 0.2812 & 0.24488 \\
\hline 7 & 0.5711 & 0.3041 & 0.4289 & 0.6959 & 0.5382 & 0.4181 & 0.4782 & 0.2511 & 0.22706 \\
\hline 8 & 0.6711 & 0.1622 & 0.3289 & 0.8378 & 0.6032 & 0.3737 & 0.4885 & 0.2672 & 0.22128 \\
\hline 9 & 0.2263 & 0.7365 & 0.7737 & 0.2635 & 0.3926 & 0.6549 & 0.5237 & 0.2356 & 0.28808 \\
\hline 10 & 0.2474 & 0.4595 & 0.7526 & 0.5405 & 0.3992 & 0.4805 & 0.4398 & 0.2118 & 0.22805 \\
\hline 11 & 0.3079 & 0.6351 & 0.6921 & 0.3649 & 0.4194 & 0.5781 & 0.4988 & 0.2335 & 0.26525 \\
\hline 12 & 0.2132 & 0.5405 & 0.7868 & 0.4595 & 0.3885 & 0.5211 & 0.4548 & 0.2142 & 0.24067 \\
\hline 13 & 0.0053 & 0.9189 & 0.9947 & 0.0811 & 0.3345 & 0.8605 & 0.5975 & 0.2461 & 0.35133 \\
\hline 14 & 0.0000 & 0.9054 & 1.0000 & 0.0946 & 0.3333 & 0.8409 & 0.5871 & 0.2428 & 0.34431 \\
\hline 15 & 0.0711 & 0.8108 & 0.9289 & 0.1892 & 0.3499 & 0.7255 & 0.5377 & 0.2313 & 0.30640 \\
\hline 16 & 0.0605 & 1.0000 & 0.9395 & 0.0000 & 0.3473 & 1.0000 & 0.6737 & 0.2716 & $\mathbf{0 . 4 0 2 1 0}$ \\
\hline
\end{tabular}


Table 10. Results of Simultaneous Machining Characteristic Optimization

\begin{tabular}{|c|c|c|c|}
\hline Method & Optimization & $\begin{array}{c}\text { Optimal parameter level } \\
\text { combination }\end{array}$ & Experimental values \\
\hline Case1 & $\begin{array}{c}\text { For balanced } \mathrm{Ra} \\
\text { and } \mathrm{Cs}\end{array}$ & $\begin{array}{c}\mathrm{T}_{\mathrm{ON}}=15 \mu \mathrm{s}, \mathrm{IP}=9 \mathrm{~A}, \mathrm{SV}=5 \mathrm{~V} \\
\text { and } \mathrm{WT}=12 \mathrm{Kg}-\mathrm{f}\end{array}$ & $\begin{array}{c}\mathrm{Ra}=1.535 \mu \mathrm{m} \\
\mathrm{Cs}=0.97 \mathrm{~mm} / \mathrm{min}\end{array}$ \\
\hline Case 2 & $\begin{array}{c}\text { For better surface } \\
\text { roughness }\end{array}$ & $\begin{array}{c}\mathrm{T}_{\mathrm{ON}}=15 \mu \mathrm{s}, \mathrm{IP}=9 \mathrm{~A}, \mathrm{SV}=5 \mathrm{~V} \\
\text { and WT }=12 \mathrm{Kg}-\mathrm{f}\end{array}$ & $\begin{array}{c}\mathrm{Ra}=1.535 \mu \mathrm{m} \\
\mathrm{Cs}=0.97 \mathrm{~mm} / \mathrm{min}\end{array}$ \\
\hline Case 3 & $\begin{array}{c}\text { For better cutting } \\
\text { speed }\end{array}$ & $\begin{array}{c}\mathrm{T}_{\mathrm{ON}}=25 \mu \mathrm{s}, \mathrm{IP}=12 \mathrm{~A}, \mathrm{SV}=15 \mathrm{~V} \\
\text { and } \mathrm{WT}=12 \mathrm{Kg}-\mathrm{f}\end{array}$ & $\begin{array}{c}\mathrm{Ra}=3.32 \mu \mathrm{m} \\
\mathrm{Cs}=2.32 \mathrm{~mm} / \mathrm{min}\end{array}$ \\
\hline
\end{tabular}

\subsection{Analysis of Machined Surface after WEDM}

Figure 3 shows the SEM image of the surface of specimen 2 that is machined under the condition $\mathrm{T}_{\mathrm{ON}}=15 \mu \mathrm{s}, \mathrm{IP}=9 \mathrm{~A}, \mathrm{SV}=15 \mathrm{~V}$ and $\mathrm{WT}=12 \mathrm{Kg}-\mathrm{f}$. The surface roughness of the specimen machined under this condition is found to be $1.535 \mu \mathrm{m}$ and cutting speed is at $0.97 \mathrm{~mm} / \mathrm{min}$. From Figure 3 it is observed that the surface is smooth and no evidence of debris, cracks and craters, this may be due to the availability of low discharge energy and also the machining was done with low Cs resulting in smooth surface [21]. Figure 4 shows the SEM image of the surface of specimen16, machined under the conditions $\mathrm{T}_{\mathrm{ON}}$ $=25 \mu \mathrm{s}, \mathrm{IP}=12 \mathrm{~A}, \mathrm{SV}=15 \mathrm{~V}$ and $\mathrm{WT}=12 \mathrm{Kg}-\mathrm{f}$ and the surface is observed to be very rough with craters, debris and pores, which may be due to the availability of high discharge energy causing more amount of heat generation resulting in melting of more amount of material and the dielectric fluid may not clear the material and there by deposition of debris and the molten material during solidification. As machining was done at high Cs may be resulted in poor surface finish [22].

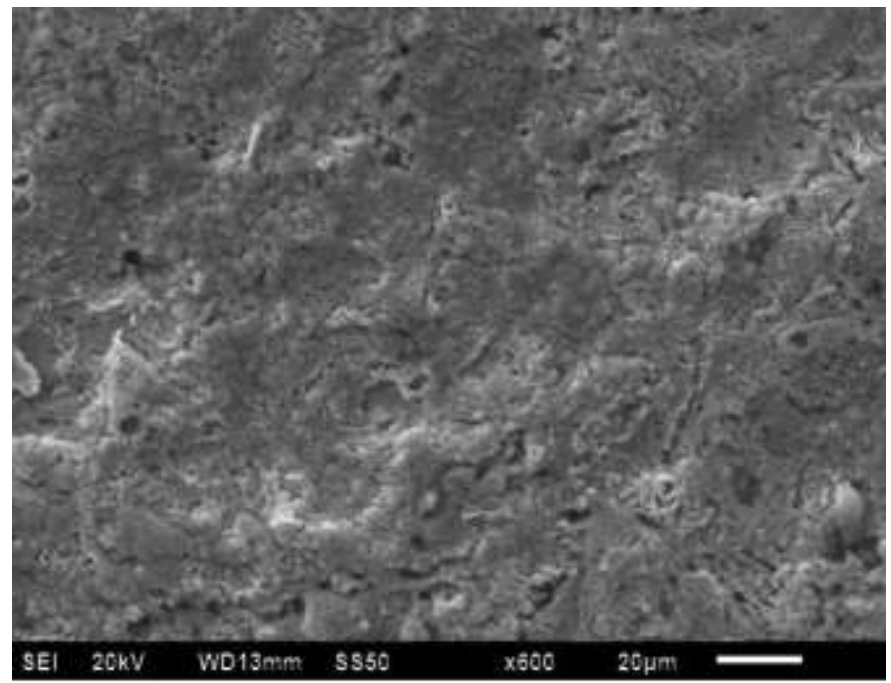

Figure 3. SEM Image of the Specimen 2 Machined at TON $=15 \mu \mathrm{s}, \mathrm{IP}=9 \mathrm{~A}$, $S V=5 \mathrm{~V}$ and $\mathrm{WT}=12 \mathrm{Kg}-\mathrm{f}$ 


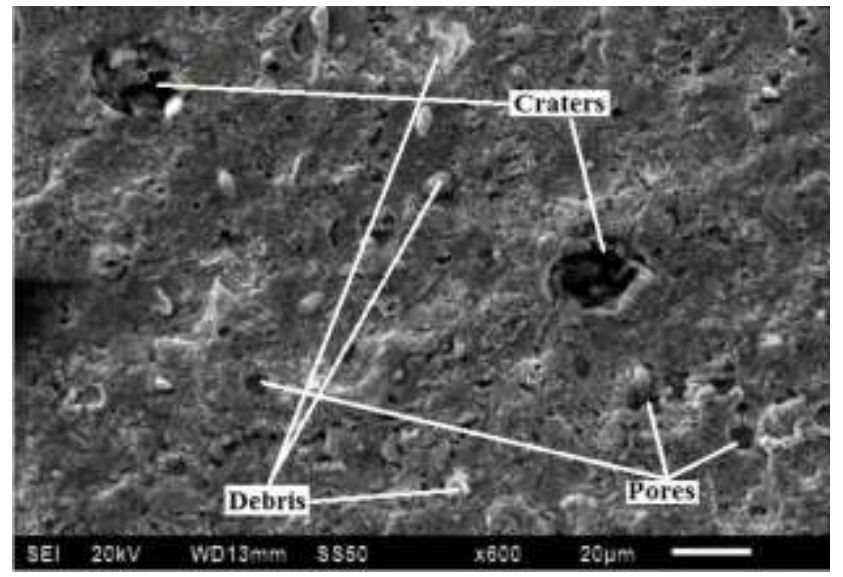

\section{Figure 4. SEM Image of Specimen 16 Machined at TON = 25 $\mu \mathrm{s}, \mathrm{IP}=12 \mathrm{~A}$, $S V=15 V$ and $W T=12 \mathrm{Kg}-f$}

\section{Conclusions}

The effect of $\mathrm{T}_{\mathrm{ON}}$, IP, SV and WT were experimentally investigated on machining 316 L SS by using wire EDM. From ANOVA $\mathrm{T}_{\mathrm{ON}}$, and IP are found to be most significant factors effecting $\mathrm{Ra}$ and $\mathrm{Cs}$. This paper presents the individual optimal parametric combination for obtaining good $\mathrm{Ra}$ and $\mathrm{Cs}$. The proposed regression model successfully predicts the values in machining. Also simultaneous optimization for obtaining good Ra and Cs is performed using Taguchi grey relational analysis and the optimal combination is also obtained. The SEM image of the specimen machined at this optimal combination showed the surface to be smooth and free from craters, cracks and irregularities.

\section{References}

[1] J. Kamal, G. Sandeep and A. Aman, "Simultaneous optimization of material removal rate and surface roughness for WEDM of WC-Co composite using grey relational analysis along with Taguchi method", International Journal of Industrial Engineering Computations, vol. 2, (2011), pp. 479-490.

[2] K. Kanlayasiri and S. Boonmung, "Effects of wire EDM machining variables on surface roughness of newly developed DC 53 die steel: Design of experiments and regression model", Journal of materials processing technology. vol. 192, no. 193, (2007), pp. 459-464.

[3] A. R. Bagherian, R. Teimouri, B. M. Ghasemi and Z. Leseman, "Application of Taguchi, ANFIS and grey relational analysis for studying, modeling and optimization of wire EDM process while using gaseous media", International journal of Adv Manufacturing Technology, vol. 71, (2014), pp. 279-295.

[4] S. Sarkar, M. Sekh, S. Mitra and B. Bhattacharyya, "Modeling and optimization of wire electrical discharge machining of $\gamma$-TiAl in trim cutting operation", Journal of Mater Process Technology, vol. 205, no. 200, (2008), pp. 376-387.

[5] L. Lia, Y. B. Guo, X. T. Wei and W. Li, "Surface integrity characteristics in wire-EDM of inconel 718 at different discharge energy", Procedia, Elsevier CIRP, vol. 6, (2013), pp. 220-225.

[6] Y. K. Lok and T. C. Lee, "Processing of EDM advanced ceramics using the wire cut EDM process", Journal of material processing Technology, vol. 63, no. 1-3, (1997), pp. 839-843.

[7] M. Aminollah, F. T. Alireza, E. Ehsan and K. Davoud, "A new approach to surface roughness and roundness improvement in wire electrical discharge turning based on statistical analyses", Int J Adv Manuf Technol, vol. 39, (2007), pp. 64-73.

[8] S. Sarkar, S. Mitra and B. Bhattacharyya, "Parametric optimization of wire electrical discharge machining of titanium aluminide alloy", Journal of materials processing technology, vol. 159, (2008), pp. 286-294.

[9] S. S. Mahapatra and A. Patnaik, "Optimization of wire electrical discharge machining (WEDM) process parameters using Taguchi method", Int. J Adv Manuf Technology, vol. 34, (2007), pp. 911-925.

[10] J. T. Huang, Y. S. Liao and W. J. Hsue, "Determination of finish cutting operation number and machining parameters setting in wire electrical discharge machining", Journal of materials processing technology, vol. 87, (1999), pp. 69-81.

[11] C. J. Tzeng, Y. H. Lin and Y. K. Yang, "Optimization of turning operations with multiple performance characteristics using the Taguchi method and grey relational analysis", Journal of Mater Process Tech, vol. 209, (2009), pp. 2753-2759. 
[12] P. S. Kao and H. Hocheng, "Optimization of electrochemical polishing of stainless steel by grey relational analysis", Journal of Mater Process Technology, vol. 140, (2003), pp. 255-262.

[13] P. Raju, M. M. M. Sarcar and B. Satyanarayana, "Optimization of wire electric discharge machining parameters for surface roughness on 316L Stainless Steel using full factorial experimental design", Procedia material science, Elsevier, vol. 5, (2014), pp. 1670-1676.

[14] R. Bobbili, V. Madhu and A. K. Gogia, "Modelling and analysis of material removal rate and surface roughness in wire-cut EDM of armour materials", Engineering Science and Technology, Elsevier, vol. 18, (2015), pp. 664-668.

[15] J. L. Yang and J. C. Chen, "A systematic approach for identifying optimum surface roughness performance in end-milling operations", Journal of Industrial Technology, vol. 17, (2007), pp. 1-8.

[16] S. Lal, S. Kumar, Z. A. Khan and A. N. Siddiquee, "Multi-response optimization of wire electrical discharge machining process parameters for Al7075/Al2O3/SiC hybrid composite using Taguchi-based grey relational analysis", Proc IMechE Part B: J Engineering Manufacture, (2014), pp. 1-9.

[17] J. T. Huang and Y. S. Liao, "Optimization of machining parameters of Wire-EDM based on Grey relational and statistical analyses", International Journal of Production Research, vol. 41, no. 8, (2003), pp. 1707-1720.

[18] A. Goswami and J. Kumar, "Investigation of surface integrity, material removal rate and wire wear ratio for WEDM of Nimonic 80A alloy using GRA and Taguchi method", International Journal of Engineering Science and Technology, Elsevier, vol. 17, (2014), pp. 173-184.

[19] L. B. Abhang and M. Hameedullah, "Determination of optimum parameters for multi-performance characteristics in turning by using grey relational analysis", Int J Adv Manuf Technol., vol. 28, (2006), pp. 450-455.

[20] R. Khanna, A. Kumar, M. Pal Garg, A. Singh and N. Sharma, "Multiple performance characteristics optimization for Al 7075 on electric discharge drilling by Taguchi grey relational theory", Journal of Ind Eng Int., vol. 11, (2015), pp. 459-472.

[21] P. Srinivasa Rao, K. Ramji and B. Satyanarayana, "Surface integrity of wire EDMed aluminum alloy: A comprehensive experimental investigation", Journal of King Saud University-Engineering Sciences, Elsevier Journal. https://doi.org/10.1016/j.jksues, (2017).12.001.

[22] M. Boujelbene, E. Bayraktar, Tebni and W. S. Ben Salem, "Influence of machining parameters on the surface integrity in electrical discharge machining", Archives of materials science and engineering, vol. 37, no. 2, (2009), pp. 110-116.

Authors

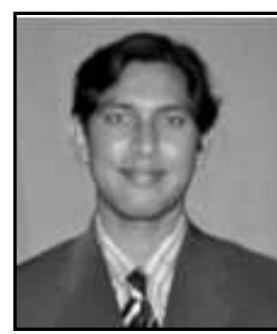

P. Raju, received his ME (CAD/CAM) and B.E in Mechanical Engineering from Andhra University. He is presently working as an Assistant Professor in the Department of Mechanical Engineering in GITAM deemed to be university, Visakhapatnam.

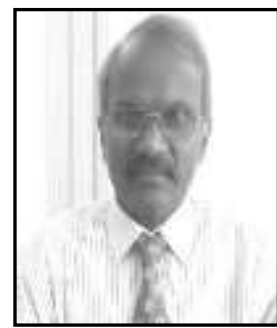

Dr. CH. Ratnam, received his Ph.D. from IIT Madras, M.E(MD) and B.E in Mechanical Engineering from Andhra University. He is presently working as Professor and Head of the Department in the Department of Mechanical Engineering, A.U. College of Engineering, Andhra University, Visakhapatnam.

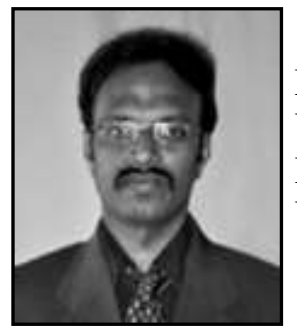

Dr. Dora Siva Prasad, received his PhD from Andhra University M.E(MD) and B.E in Mechanical Engineering from Andhra University. He is presently working as an Associate Professor in the Department of Mechanical Engineering in GITAM deemed to be University, Visakhapatnam. 
International Journal of Advanced Science and Technology

Vol.114 (2018) 